\title{
Measurement and Prediction of Electromagnetic Radiation Exposure Level in a University Campus
}

\author{
Esin KARPAT ${ }^{*}$, M. Rafet BAKCAN
}

\begin{abstract}
The importance of electromagnetic (EM) sources in human life has been increasing with the development of technology. EM radiation triggers some problems in our life such as EM interference and human health problems. EM radiation level which is emitted by the base station increases in proportion to the density of population in a region. EM exposure is higher in areas where people are highly concentrated such as hospitals, military barracks, schools, shopping malls, than in any other region. It is important to show sustained concern about the EM radiation intensity in these areas to keep the levels under the permissible limits. In this study, electric field values are measured statically at locations where the population density is too high, to examine the electric field intensity levels throughout the campus. Besides, two different artificial neural models (ANN) are developed to estimate the electric field values of random locations which are specific regions for electromagnetic exposure. Moreover, measurement results and estimated results are evaluated within the limits defined by national (ICTA) and international (ICNIRP) standards. Finally, the EM exposure map is constructed with data that is average electric field intensity versus measurement locations.
\end{abstract}

Keywords: artificial neural network; electrical field; electromagnetic radiation; electromagnetic field measurement; prediction method

\section{INTRODUCTION}

The concept of electric and magnetic fields has begun to take place in human life with the discovery of electric power. High-frequency work has been done in many areas especially for mobile phone communications from the early 20 th century to today's radio communication [1].

The intense use of Wireless Communication Wireless LANs, Global System for Mobile communications (GSM), TV-radio transmitters, base stations, etc. for personal or commercial purposes lead scientists to research for the risk factor of electromagnetic pollution for human health and environment. These researches have led to the result that the electromagnetic radiation, density, and frequency of sources should be under control as described by the standards [2]. The advantages of the mobile phone such as: instant internet connections, instant communication, instant access to data, listening to music, etc., have made it a complementary part of our everyday life which in turn led to an increase in mobile phone users. Despite its advantages, mobile phones also have many harmful aspects [3]. The number of mobile phone users has increased by $16 \%$ since 2010 and today more than 74 million users exist in Turkey. The increase in the number of mobile phone users triggers to raise the electromagnetic field level in the medium [4]. The mobile phone users are exposed to electromagnetic radiation from both mobile phone and base stations [5].

Since it is accepted to be the fourth environmental pollution factor, it has become the most concerning problem for human health. Since the consequences of longterm exposure are still unknown it is important to measure and analyse the electromagnetic radiation levels periodically [6].

The low power levels of WLAN $(2,4 \mathrm{GHz})$ electromagnetic coverage also has to be analysed to clarify whether it is also a risk for electromagnetic pollution for indoor propagation [2]. People are unintentionally exposed to these uncontrollable/unavoidable electromagnetic fields. Epidemiological studies show that there is a relationship between electromagnetic exposure and cancer [7-13]. There are many studies on the effects of electromagnetic radiation on human beings and animal health in the literature. Experiments on mice show that the electromagnetic field caused by $3 \mathrm{G}$ mobile phones causes differences in the salivary glands of mice [14]. The possible biological effects of low and high-frequency electromagnetic fields about reproductive capacities, blood levels and immune systems of living organisms were also observed [15]. Chakrabarty and Singh numerically modelled the human body and evaluated the safety distances for base stations by obtaining the specific absorption rates of different regions on the body which face possible electromagnetic sources [16].

Although there is no conclusive evidence that shows the harmful effects of EM waves, electromagnetic radiation exposure limits are limited by national $[17,18]$ and international [19-21] organizations, to take precautions against possible threats. The frequency, magnitude, and duration of exposure of electromagnetic waves are parameters to be considered in analysing the effects of electromagnetic radiation on living organisms [22]. In crowded and permanent living spaces such as schools [22], hospitals, shopping malls, crowded residential areas [23, $24]$, the user concentration can vary with the days of the week and hours of the day [25]. Therefore, the electric field intensity in the environment can change. Electromagnetic field EMF can provide information about the diseases caused by EMF and their regional distribution [26]. There are many studies in the literature that have been conducted to examine the variation of electric field intensities in continuous and crowded living areas. For the same purpose, several studies have been carried out to measure the electromagnetic radiation levels of base stations in different city centres such as Erciyes [26], Nablus [27], Ordu [28], Black Sea Region [6], and Serbia [29]. Carmounted measurements are performed to measure the radiation exposure over large geographical areas [30, 31].

In this study, electric field values in the $27 \mathrm{MHz}-3$ $\mathrm{GHz}$ frequency range are measured statically for six minutes' duration at the determined locations to evaluate the EM variation in the central campus of the Bursa Uludag University. This campus has more than 60000 students as well as a medical faculty hospital which is visited by 
thousands of people every day. Therefore, it is important to detect the EM value and keep it below the national standards. Prediction of the total average electric field value is carried out by artificial neural network models and multiple linear regression analysis considering the latitude, longitude and frequency indexes of the measurement locations. Besides, measured values are assessed within the limits which are determined by national and international standards. The resulting map is constructed utilizing the measured electric field values.

\section{MATERIAL AND METHOD \\ 2.1 Measurement}

The location and duration of measurement have importance in terms of the accuracy of the data to be obtained in the detection of electromagnetic exposure. Since the entity most affected by electromagnetic exposure is human, the measurement location of the device should be determined considering the human body and should be chosen according to the highest exposure point of humans. Therefore, the antenna of the devices should be positioned $1.5 \mathrm{~m}$ above the ground to perform the measurements precisely [32].

In this study, measurements are performed statically with SRM 3006 and isotropic antenna with a frequency range of $27 \mathrm{MHz}-3 \mathrm{GHz}$. The measured values are reported with position and time data simultaneously due to the integrated GPS module in SRM 3006. The service table of frequency values which is in the range of $27 \mathrm{MHz}$ to 3 $\mathrm{GHz}$ is divided into 50 frequency indices and measurements are performed.

The measurements are carried out statically for a 6 minute duration as required by the ICTA standards and for each location, 224 measurement samples are stored. Also, the average field values for 224 samples are calculated (Eq. (1)) and reported for each measurement period.

$E_{a v}=\frac{\sum_{1}^{224} \sqrt{E_{r}^{2}+E_{\theta}^{2}+E_{\varnothing}^{2}}}{224}$

For each measurement location within the central campus, the total average electric field value, considering the contribution of 50 frequency indices mentioned in the service table, is calculated by Eq. (2).

$$
E_{a v}=\sqrt{\sum_{n=1}^{50} E_{n}^{2}}
$$

The measurements are generally performed around Wi-Fi locations and base stations. There are two base stations on the campus and the distance between them is approximately $1 \mathrm{~km}$. Some of the measurements are carried out at three different locations on three different arcs with a radial distance of $120 \mathrm{~m}, 150 \mathrm{~m}$ and $180 \mathrm{~m}$ from each base station. The arc length between measurement locations on each arc is equal. The rest of the measurements are carried out near buildings such as faculty buildings, refectory, cafes, gym saloon, library, and banking house.

\subsection{National and International Standards}

Electromagnetic field sources have to radiate under certain limit-values which are determined by national and international regulations. ICNIRP has determined these limit values by considering the thermal effects of EM fields on the human body. The limit values of the E permitted in Turkey for single and multiple devices are given in Tab. 1. The regulations published by ICTA are based on the reference levels of ICNIRP (Tab. 2).

\begin{tabular}{|c|c|c|}
\hline $\begin{array}{c}\text { Frequency } \\
\text { Range / MHz }\end{array}$ & $\begin{array}{c}\text { E-Field Strength } \\
\text { (single device) } / \mathrm{V} / \mathrm{m}\end{array}$ & $\begin{array}{l}\text { E-Field Strength } \\
\text { (all devices) } / \mathrm{V} / \mathrm{m}\end{array}$ \\
\hline $0.010-0.15$ & 19,3 & 65,25 \\
\hline $0.15-1$ & 19,3 & 65,25 \\
\hline $1-10$ & $19,3 / \mathrm{f}^{0.5}$ & $65,25 / \mathrm{f}^{0,5}$ \\
\hline $10-400$ & 6,2 & 21 \\
\hline $400-2000$ & $0,305 \times \mathrm{f}^{0,5}$ & $1,03 \times \mathrm{f}^{0,5}$ \\
\hline $2000-60000$ & 13,5 & 45,75 \\
\hline
\end{tabular}

Table 2 Reference levels of ICNIRP (1998) for general public exposure to timevarying electric field [19]

\begin{tabular}{|c|c|}
\hline Frequency Range $/ \mathrm{MHz}$ & E-Field Strength $/ \mathrm{V} / \mathrm{m}$ \\
\hline $0.15-1$ & 87 \\
\hline $1-10$ & $87 / \mathrm{f}^{0,5}$ \\
\hline $10-400$ & 28 \\
\hline $400-2000$ & $1.375 \times \mathrm{f}^{0,5}$ \\
\hline $2-300$ & 61 \\
\hline
\end{tabular}

\subsection{Artificial Neural Network (ANN)}

Artificial neural networks are based on neurons in the human brain. The mathematical expression of neuron $\mathrm{k}$ is given in Eq. (2).

$u_{k}=\sum_{i=1}^{m} w_{k i} x_{j}$

In Eq. (3), $\left(x_{1}, x_{2}, x_{3}, \ldots, x_{m}\right)$ are the input signals and $\left(w_{k 1}, w_{k 2}, w_{k 3}, \ldots, w_{k m}\right)$ are the respective synaptic weights of the $k^{\text {th }}$ neuron.

$y_{k}=\varphi\left(u_{k}+b_{k}\right)$

In Eq. (4), $b_{k}$ is the bias and it is an external parameter. Also, $\varphi$ is the activation function of the equation. When considering Eq. (5) and Eq. (6), $y_{k}$ is the output signal of neuron.

The sigmoid function is used as a common S-shaped activation function in the structure of artificial neural networks. The sigmoid function is given in Eq. (5).

$\varphi(v)=\frac{1}{1+e^{-a v}}$

" $a$ " is the slope parameter of the sigmoid function. Sigmoid functions of different slopes can be obtained by varying the parameter $a$. The sigmoid activation function range is $(0.0+1.0)$. However, in some cases, this range can be needed to be extended as $(-1,1)$. In this case, the general hyperbolic tangent function which is defined in Eq. (6) can be used. 
$\varphi(v)=\tan h(v)$

The Levenberg-Marquardt is the most commonly used training algorithm that allows calculating the training speed of the network independently of the Hessian matrix calculation. The Hessian matrix calculated in typical feed forward network training is expressed in Eq. (7).

$H=J^{\mathrm{T}} J$

The gradient is calculated as:

$g=J^{\mathrm{T}} e$

In Eq. (8), $\mathrm{J}$ is the Jacobian matrix consisting of first derivatives of network errors with respect to weights and biases. The Jacobian matrix is computed by a standard backpropagation technique. The Levenberg-Marquardt algorithm can be expressed as in Eq. (9) with the Hessian matrix approach, as the Newton method.

$x_{k-1}=x_{k}-\left(J^{\mathrm{T}} J+\mu I\right)^{-1} J^{T} e$

When damping parameter $\mu$ is zero, Eq. (9) is the Newton method. Besides, when $\mu$ increases, it becomes gradient descent. The performance of the function is increased by decreasing the damping factor after each step and by increasing after every ambiguous step [33].

The learning process of the neural network involves adjusting network weights and bias values to optimize network performance. The default network performance function is the mean square error (MSE), which calculates the square of the difference between output y (estimated value) and target $t$ (target value) as in Eq. (10).

$$
M S E=\frac{1}{N} \sum_{i=1}^{n} e_{i}^{2}=\frac{1}{N} \sum_{i=1}^{N}\left(t_{i}-y_{i}\right)^{2}
$$

\subsection{Multiple Linear Regression Analysis (MLRA)}

The main purpose of multiple linear regression analysis is to determine the relationship between the dependent variable and multiple independent variables. MLRA allows investigating the effect of other independent variables on the dependent variable. The general expression of regression is shown in Eq. (11) where $\varepsilon$ is the random error, $\left(x_{1}, x_{2}, x_{3}, \ldots, x_{n}\right)$ are the independent variables, and $\left(\beta_{1}, \beta_{2}, \beta_{3}, \ldots, \beta_{n}\right)$ are the estimated regression coefficients that represent the change in the output (dependent) variable $y$ relative to a change in the corresponding independent variable.

$y=\beta_{0}+\beta_{1} x_{1}+\beta_{2} x_{2}+\beta_{3} x_{3}+\ldots+\beta_{n} x_{n}+\varepsilon$

The general matrix form of MLRA is expressed as:

$$
X=\left[\begin{array}{ccc}
1 & \ldots & x_{1} \\
\ldots & \ldots & \ldots \\
1 & \ldots & x_{n}
\end{array}\right], \beta=\left[\begin{array}{c}
\beta_{0} \\
\ldots \\
\beta_{n}
\end{array}\right], \varepsilon=\left[\begin{array}{c}
\varepsilon_{0} \\
\ldots \\
\varepsilon_{n}
\end{array}\right]
$$

The coefficient matrix in Eq. (12) is calculated by [34].

$$
\beta=(X X)^{-1} X Y=\left[\begin{array}{c}
\frac{\sum x_{i}^{2} \sum y_{i}-\sum x_{i} \sum x_{i} y_{i}}{\sum_{i=1}^{n}\left(x_{i}-\bar{x}\right)^{2}} \\
\frac{\sum\left(x_{i}-\bar{x}\right)\left(y_{i}-\bar{y}\right)}{\left(x_{i}-\bar{x}\right)^{2}}
\end{array}\right]
$$

\section{DATA ANALYSIS}

When measured electric field values are considered, it is observed that the electric field values at 47 locations are below $0.5 \mathrm{~V} / \mathrm{m}$, at 8 locations are between $0.5 \mathrm{~V} / \mathrm{m}$ and 1 $\mathrm{V} / \mathrm{m}$, at 11 locations are between $1 \mathrm{~V} / \mathrm{m}$ and $2 \mathrm{~V} / \mathrm{m}$, at 11 locations are between $2 \mathrm{~V} / \mathrm{m}$ and $3 \mathrm{~V} / \mathrm{m}$, at 4 locations are between $3 \mathrm{~V} / \mathrm{m}$ and $4 \mathrm{~V} / \mathrm{m}$ and at 2 locations are above 4 $\mathrm{V} / \mathrm{m}$.

The measurement results, relative to 50 different frequency indices, are calculated by classifying them into 7 frequency bands as given in Tab. 3 for MLRA method.

The MLRA method is used to analyze the measured data to determine the effect of the measured values of each frequency band on the total EM level (Eq. (14)).

$$
\begin{aligned}
& E_{\text {total }}=F M \cdot \beta_{1}+V H F \cdot \beta_{2}+U H F \cdot \beta_{3}+G S M \cdot \beta_{4}+ \\
& +U M T S \cdot \beta_{5}+L T E \cdot \beta_{6}+W L A N \cdot \beta_{7}+O T H E R S \cdot \beta_{8}
\end{aligned}
$$

Table 3 Frequency bands and the corresponding MLRA coefficients

\begin{tabular}{|c|c|c|c|}
\hline Frequency & Frequency Band / MHz & $\begin{array}{c}\text { Coefficient } \\
\text { Notation }\end{array}$ & $\begin{array}{c}\text { Coefficient } \\
\text { Value }\end{array}$ \\
\hline$F M$ & $87-108$ & $\beta_{1}$ & $-0,52002$ \\
\hline$V H F$ & $140-300$ & $\beta_{2}$ & $-1,59637$ \\
\hline$U H F$ & $400-790$ & $\beta_{3}$ & $-1,65938$ \\
\hline$G S M$ & $791-959,9$ & $\beta_{4}$ & 0,764872 \\
\hline$U M T S$ & $1710,1-2170$ & $\beta_{5}$ & 0,640741 \\
\hline$W I F I$ & $2400-2499$ & $B_{6}$ & 0,04468 \\
\hline LTE & $2500-2670$ & $B_{7}$ & 0,510623 \\
\hline OTHERS & Other from above & $B_{8}$ & 2,385177 \\
\hline
\end{tabular}

For instance, $F M$ refers to the measured electric field value at $F M$ band $(\mathrm{V} / \mathrm{m})$ and $\beta_{1}$, the MLRA coefficient for $F M$ contribution, is equal to 0,52002 .

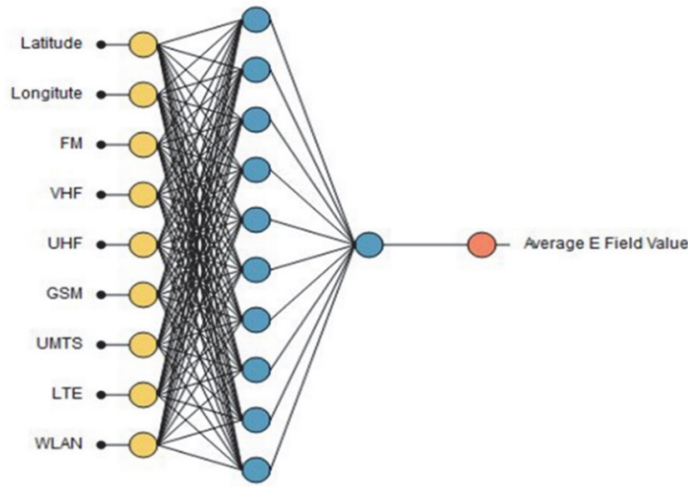

Figure 1 The layers of artificial neural network model-1 (ANN-1).

In this study, two different models are also created for the estimation. In ANN-1 model there are nine inputs in the input layer which are latitude, longitude of measurement locations and the measured electric field values of the classified frequency bands (Tab. 3). The estimation takes 
place in the hidden layer and the average total electric field value is estimated in the output layer (Fig. 1). In the ANN2 model, shown in Fig. 2, there are two data in the input layer which are only latitude and longitude of the measurement location and the average total electric field value is estimated in the output layer. In ANN-2 model, only the total average electric field is estimated.

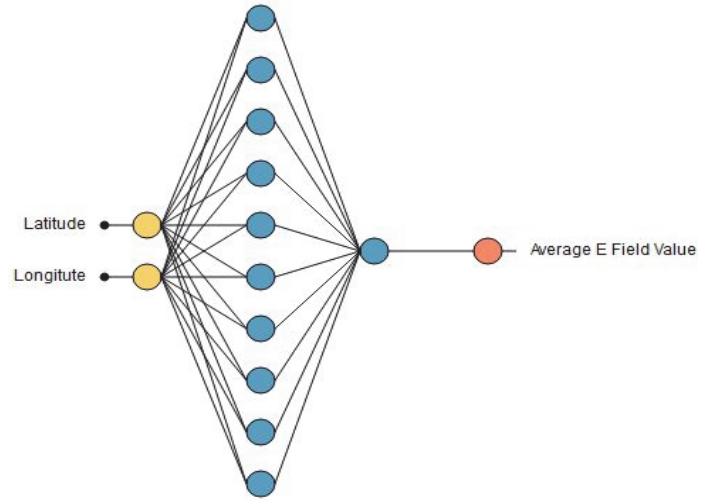

Figure 2 The layers of artificial neural network model-2 (ANN-2)

\section{$4 \quad$ RESULTS AND DISCUSSION}

Each frequency band in Tab. 3 is estimated according to ANN-1 model. The input layers are latitude, longitude and the electric field contribution of other frequency values except for the estimated frequency. For instance, to estimate the electrical field value radiated at $F M$ as in Fig. 3 , the input layer of the ANN-1 model has latitude, longitude, and the measured electric field values at $V H F$, $U H F$, GSM, UMTS, LTE and WLAN frequency bands, as inputs. Fig. 4, Fig.5, Fig.6, Fig.7, Fig.8 and Fig. 9 show the comparison of the estimated and the measured values at GSM, LTE, UHF, UMTS, VHF, and WiFi frequency bands with ANN-1 estimation method, respectively.

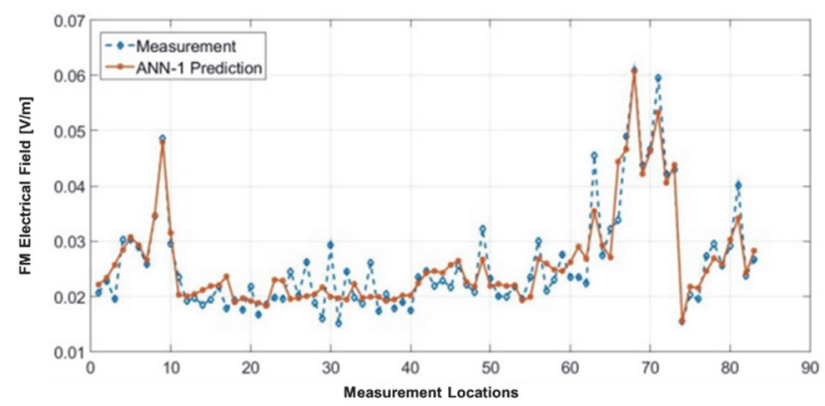

Figure 3 The comparison of measured and estimated $E$ field values at FM band

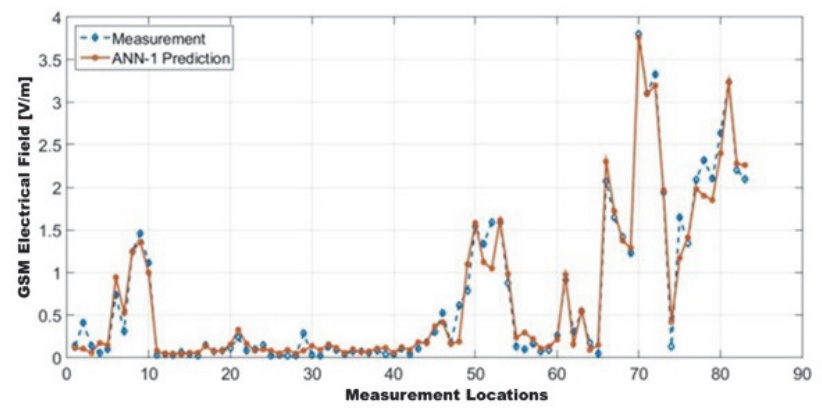

Figure 4 The comparison of measured and estimated $E$ field values at GSM band

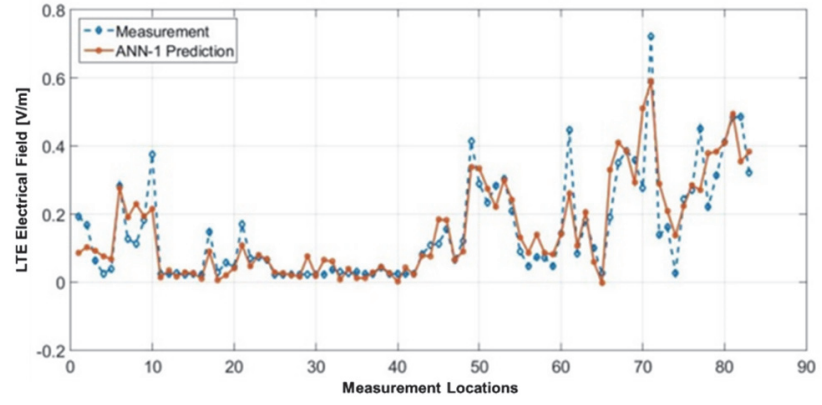

Figure $\mathbf{5}$ The comparison of measured and estimated $\mathrm{E}$ field values at LTE band

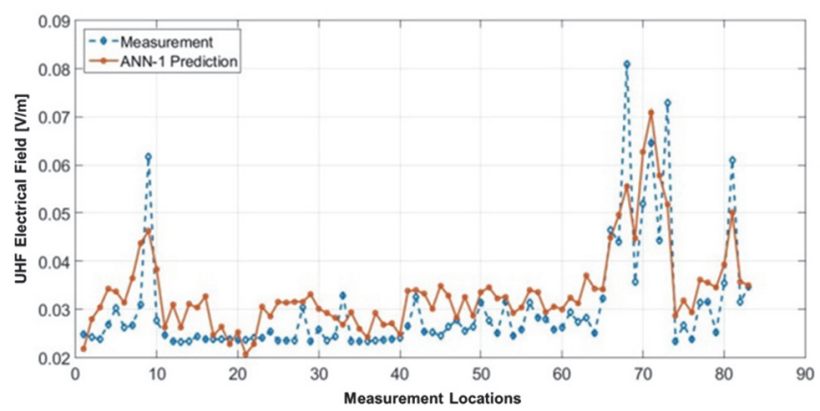

Figure 6 The comparison of measured and estimated $E$ field values at UHF band

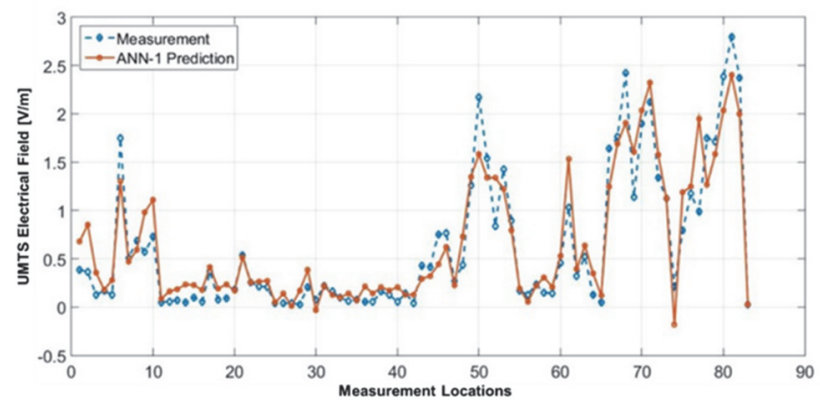

Figure 7 The comparison of measured and estimated $E$ field values at UMTS band

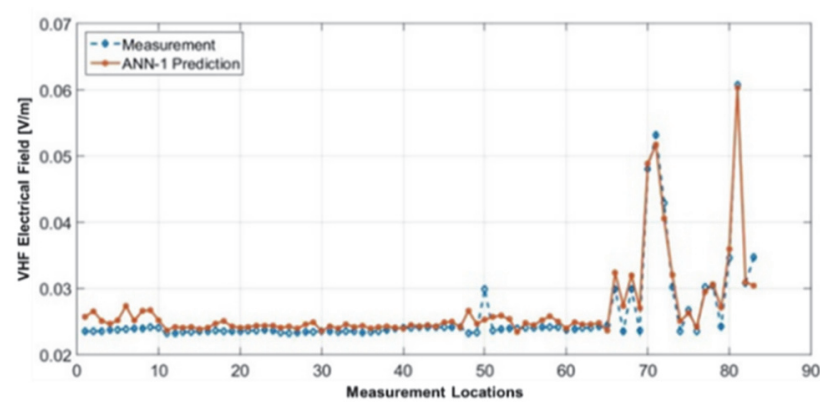

Figure 8 The comparison of measured and estimated $\mathrm{E}$ field values at VHF band

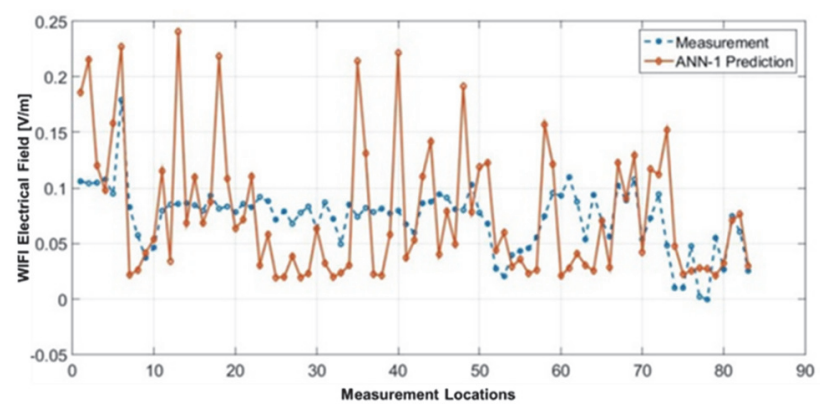

Figure 9 The comparison of measured and estimated $\mathrm{E}$ field values at WiFi band 


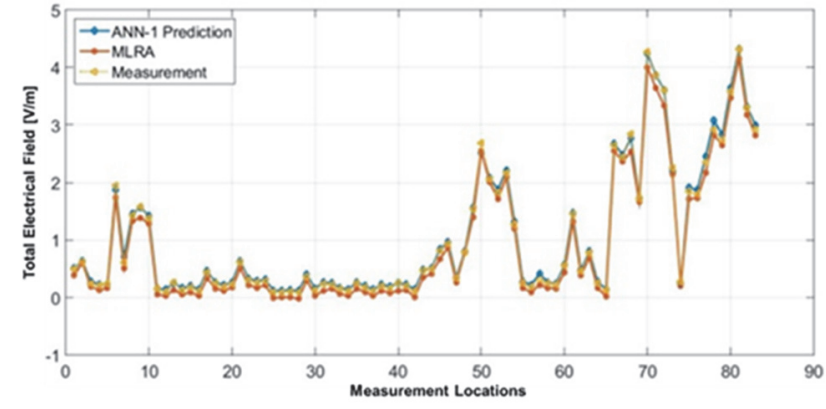

Figure 10 The comparison of measured total E-field values with the values estimated by ANN-1 and MLRA methods

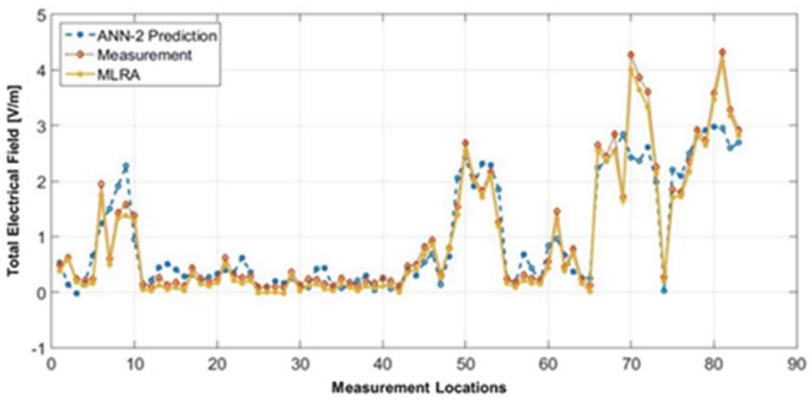

Figure 11 The comparison of measured total E-field values with the values estimated by ANN-2 and MLRA methods.

The estimated electric field values obtained by ANN1 and MLRA methods are compared with the measured values (Fig. 10). In Fig.11 the estimation results obtained by the ANN-2 method are compared with the measured ones and the MLRA results.

Table 4 The correlation coefficients between ANN-1, MLRA and Measured data.

\begin{tabular}{|c|c|c|c|}
\hline & ANN-1 & MLRA & Measurement \\
\hline ANN-1 & 1 & 0,999233 & 0,999443 \\
\hline MLRA & 0,999233 & 1 & 0,99937 \\
\hline Measurement & 0,999443 & 0,99937 & 1 \\
\hline
\end{tabular}

Table 5 The correlation coefficients between ANN-2, MLRA and Measured data.

\begin{tabular}{|c|c|c|c|}
\hline & ANN-2 & MLRA & Measurement \\
\hline ANN-2 & 1 & 0,926735 & 0,924468 \\
\hline MLRA & 0,926735 & 1 & 0,99937 \\
\hline Measurement & 0,924468 & 0,99937 & 1 \\
\hline
\end{tabular}

As shown in Tab. 4, the correlation coefficients between ANN-1, MLRA, and measured values are approximately $99 \%$. The correlation coefficients between ANN-2, MLRA, and measurement are approximately $92 \%$ in Tab. 5.

\section{CONCLUSION}

In this study, two different prediction structures that have different input layers are created and the estimation results are compared with the measured values. The accuracy of the results obtained by the ANN-1 method is $7.5 \%$ better than the accuracy of the results obtained by the ANN-2 method.

Measurements in the campus show that the maximum EMF value is $4.314 \mathrm{~V} / \mathrm{m}$ while the minimum is $0.084 \mathrm{~V} / \mathrm{m}$. Also, the standard deviation value of the EMF level is $1,157 \mathrm{~V} / \mathrm{m}$ while the average EMF level is $1,024 \mathrm{~V} / \mathrm{m}$.

The average electric value measured around two base stations on the campus is $3.85 \mathrm{~V} / \mathrm{m}$ while the average electric field value of other locations is $1.153 \mathrm{~V} / \mathrm{m}$. According to these data, it is determined that the contribution of locations, which are near the base station is approximately $300 \%$ higher than the other locations. The measured values of the electric field within the Bursa Uludag University Görükle campus are below the national and international standards and the maximum value is equal to $31.95 \%$ of the maximum limit value of ICTA (Fig. 12). As well as the base stations, the contributions of other electromagnetic radiation sources such as TV, FM, WIFI are also under required limit values.

Although the measurement results show that the electromagnetic field levels in Bursa Uludag University campus are below the national permitted limits, it is important to regularly measure the radiation levels of base stations to avoid the possible harmful effects of electromagnetic radiation on human in the long term exposure. As a result, sustainable measurement strategies should be developed to reduce the health risks of electromagnetic fields

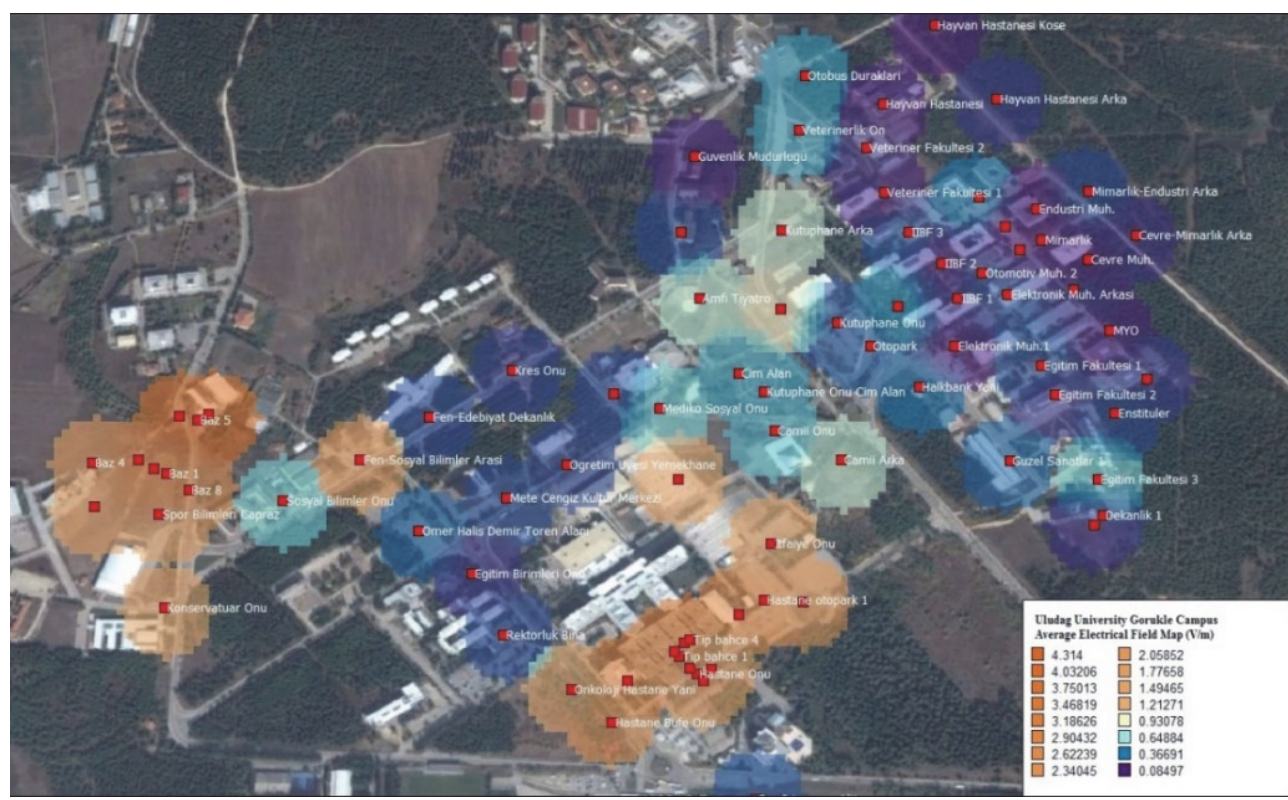

Figure 12 Average E-field map constructed on Bursa Uludag University Gorukle campus 


\section{Acknowledgements}

This Study is supported by the Bursa Uludag University AYP (MH2018/1) Project. The authors would like to thank Prof. Güneş Yilmaz, the Chair of the Electrical and Electronics Engineering Department, for providing the laboratory facilities of the department in this research.

\section{REFERENCES}

[1] Rybak, T. \& Steffka, M. (2004).Automotive electromagnetic compatibility (EMC). NewYork, NY: Springer. https://doi.org/10.1007/b101849

[2] Sen, A., Gümüsay, M., Kavas, A., \& Bulucu, U. (2008). Programming an artificial neural network tool for spatial interpolation in GIS - A Case Study for Indoor Radio Wave Propagation of WLAN: Sensors, 8(9), 5996-6014. https://doi.org/10.3390/s8095996

[3] Velmurugan, M. S. (2017). Sustainable perspectives on energy consumption, EMRF, environment, health and accident risks associated with the use of mobile phones. Renewable and Sustainable Energy Reviews., 67, 192-206. https://doi.org/10.1016/j.rser.2016.09.011

[4] Information Technologies and Communication Authority (ICTA) (2016). Annual Statistical Bulletin According to Provincial Regarding Electronic Communication Sector: Directorate of Sectoral Research and Strategy Development Department of Information Technologies and Communication Institution, Ankara.

[5] Baltrenas, P. \& Buckus, R. (2013). Measurements and analysis of the electromagnetic fields of mobile communication antennas. Measurement, 46(10), 3942-3949. https://doi.org/10.1016/j.measurement.2013.08.008

[6] Tuysuz, B. \& Mahmutoglu, Y. (2017). Measurement and mapping of the GSM-based electromagnetic pollution in the Black Sea region of Turkey. Electromagnetic Biology and Medicine., 36(2), 132-140. https://doi.org/10.1080/15368378.2016.1198801

[7] National Cancer Institute (2019). Retrieved from https://www.cancer.gov/about-cancer/causesprevention/risk/radiation/electromagnetic-fields-fact-sheet.

[8] Lai, H. (2005). Biological effects of radiofrequency electromagnetic field. Encyclopedia of Biomat, Biomed. Eng. 10, 1-8.

[9] Seyhan, N. (2002). electric fields have effect on free oxygen radical synthesis in plasma, liver, lung, kidney, testis and brain tissues. $3 r d$ International Conference: Electromagnetic Fields and Human Health and Round table: Harmonization of EMF standards in connection with the science for East-European countries Moscow and St. Petersburg.

[10] Türkkan, A., Çerezci, O., Kartal, Z., \& Pala, K. (2012). Elektromanyetik Alan ve Sağlık Etkileri. Bursa, Nilüfer Belediyesi.

[11] Gonzalez-Rubio, J., Arribas, E., Ramirez-Vazquez, R., \& Najera, A. (2017). Radiofrequency electromagnetic fields and some cancers of unknownetiology: An ecological study. Science of the Total Environment., 599-600, 834-843. https://doi.org/10.1016/j.scitotenv.2017.05.018

[12] Balmori, A. \& Hallberg, O. (2007). The urban decline of the house sparrow (Passer domesticus): a possible link with electromagnetic radiation. Electromagnetic Biology and Medicine., 26(2): 141-151. https://doi.org/10.1080/15368370701410558

[13] Khurana, V. G., Teo, C., Kundi, M., Hardell, L., \& Carlberg, M. (2009). Cell phones and brain tumors: a review including the long term epidemiologic data: Surg. Neurology., 72(3): 205-214. https://doi.org/10.1016/j.surneu.2009.01.019
[14] Aydoğan, F., İlhan, U., Emine, A., Nihat, Y., Erdinc, D., Ethem, E., S., Elcin, O., Velid, U., Arin, T., Goknur, G., O., Nesrin, S. (2015). The effect of $2100 \mathrm{MHz}$ radiofrequency radiation of $3 \mathrm{G}$ mobile phone on the parotid gland of rats. American Journal of Otolaryngology., 36(1) 39-46. https://doi.org/10.1016/j.amjoto.2014.10.001

[15] Stavroulakis, P. (2003). Biological effects of electromagnetic field. New York, NY, Springer. https://doi.org/10.1007/978-3-662-06079-7

[16] Chakraborty, C. \& Singh A. (2013). Determination of Safe Distance Limit from Cellular Base Station Radiation Exposure using SAR Analysis. International Journal of Computer Applications. 18-22.

[17] Information Technologies and Communication Authority (ICTA) (2001). Regulation on determination, measurement methods and supervision of the limit values of the electromagnetic field source from the fixed telecommunication devices operating within the frequency range of $10 \mathrm{kHz}-60 \mathrm{GHz}$. Turkey's Official Gazette, Ankara.

[18] Information Technologies and Communication Authority (ICTA). (2011). Regulation on determination, measurement methods and supervision of the limit values of the electromagnetic field source from the fixed telecommunication devices. Turkey's Official Gazette. 27912, Ankara.

[19] International Commission on Non-Ionizing Radiation Protection (ICNIRP). (2020). Guidelines for Limiting Exposure to Electromagnetic Fields (100 kHz to $300 \mathrm{GHz})$. Health Physics, 118(5). 483-524. https://doi.org/10.1097/HP.0000000000001210

[20] IEEE (2006). IEEE Standard for Safety Levels with Respect to Human Exposure to Radio Frequency Electromagnetic Fields, $3 \mathrm{kHz}$ to $300 \mathrm{GHz}$ : IEEE Std C95.1-2005 (Revision of IEEE Std C95.1-1991), 1-238. https://doi.org/10.1109/IEEESTD.2006.99501

[21] IEEE (1991). Recommended Practice for the Measurement of Potentially Hazardous Electromagnetic Fields - RF and Microwave. IEEE Std C95.3-1991. 1-112. https://doi.org/10.1109//EEESTD.1992.106979

[22] Gen, O., Bayrak, M., \& Yaldı, E. (2010). Analysis of the effects of GSM bands to the electromagnetic pollution in the RF spectrum:Progress in Electromagnetics Research, PIER.101: 17-32. https://doi.org/10.2528/PIER09111004

[23] Karpat, E., Bakcan, M., Chabbar, A., İbrahim, M., Çelik, B., \& Doğan, O. (2019). Estimating base station-based indoor and outdoor electric field levels by artificial neural networks: European Journal of Technique (EJT). 9(1), 1-12. https://doi.org/10.36222/ejt.500040

[24] Korunur, B. E. (2016). Measurement and Assessment of Long Term Electric Field Strength in Different Locations. International Journal of Advanced Research in Computer and Communication Engineering., 5(10). 455-458. https://doi.org/10.1109/ISEF.2017.8090728

[25] Seyfi, L. (2013). Measurement of electromagnetic radiation with respect to the hours and days of a week at $100 \mathrm{kHz}-$ $3 \mathrm{GHz}$ frequency band in a Turkish dwelling. Measurement. 46 (9): 3002-3009. https://doi.org/10.1016/j.measurement.2013.06.021

[26] Sorguc, U. \& Develi, I. (2012). Measurement and analysis of electromagnetic pollution generated by GSM-900 mobile phone networks in Erciyes University. Electromagnetic Biology and Medicine., 31(4), 404-415. https://doi.org/10.3109/15368378.2012.683223

[27] Mousa, A. (2011).Electromagnetic radiation measurements and safety issues of some cellular base stations in nablus. Journal of Engineering Science and Technology Review., 4(1), 35-42. https://doi.org/10.25103/jestr.041.05

[28] Kurnaz, C. \& Bozkurt, M. (2016). Measurement and evaluation of electromagnetic pollution levels in Ünye District of Ordu. Journal of New Results in Science, 5 
(EEB2016, Special Issue), 149-158. Retrieved from https://dergipark.org.tr/en/pub/jnrs/issue/27333/287738

[29] Koprivica M., Slavkovic V., Neskovic N., \& Neskovic A. (2015). Statistical analysis of electromagnetic radiation measurements in the vicinity of GSM/UMTS base station installed on buildings in Serbia. Radiat Prot Dosimetry., 168(4), 489-502. https://doi.org/10.1093/rpd/ncv372

[30] Aerts, S., Joseph, W., Maslanyj, M., Addison, D., Mee, T., Colussi, L., Kamer, J., \& Bolte, J. (2016). Prediction of RFEMF exposure levels in large outdoor areas through carmounted measurements on the enveloping roads. Environ. Int. 94, 482-488. https://doi.org/10.1016/j.envint.2016.06.006

[31] Liu, J., Wei, M., Li, H., Wang, X., Wang, X., \& Shi, S. (2019). Measurement and mapping of the electromagnetic radiation in the urban environment. Electromagnetic Biology and Medicine. https://doi.org/10.1080/15368378.2019.1685540

[32] EEC/REC/(02)04 (2003). Measuring Non-Ionising Electromagnetic Radiation $(9 \mathrm{kHz}-300 \mathrm{GHz}$ ). Electronic Communications Committee within the European Conference of Postal and Telecommunications Administrations.

[33] Haykin, S. (2009). Neural Networks and Learning Machines (3rd Edition), New Jersey, Pearson Education Inc.

[34] Yan, X. \& Su, X.G. (2009). Linear Regression Analysis Theory And Computing, London, World Scientific Publishing Co. https://doi.org/10.1142/6986

\section{Contact information:}

Esin KARPAT, Assist Prof. PhD

(Corresponding author)

Bursa Uludag University,

Department of Electrical and Electronics Engineering,

Bursa, 16059, Turkey

E-mail: esinoz@uludag.edu.tr

M. Rafet BAKCAN, MSc

Bursa Uludag University,

Department of Electrical and Electronics Engineering,

Bursa, 16059, Turkey

E-mail: mrafet.1992@gmail.com 